Journal of Economics and Behavioral Studies

Vol. 6, No. 12, pp. 986-1003, December 2014 (ISSN: 2220-6140)

\title{
Antecedents of Quality Information Sharing in the FMCG Industry
}

\author{
Thokozani Patmond Mbhele \\ University of KwaZulu-Natal, Governance, Westville Campus, Durban, South Africa \\ mbhelet@ukzn.ac.za
}

\begin{abstract}
Information sharing in a retail supply chain presents challenges of mapping information flow in terms of collection and transfer capabilities from one point to other internal and external users. Efficient mapping information flow seems to be dependent on information availability, velocity and the level of volatility. This would strengthen partnerships between the upstream and downstream sites of a supply chain in terms of information capturing, transformation and exchange between both internal and external supply chain users. This study examines the relative magnitude of advance economic information sharing in optimizing integrated supply chain activities in the consumer goods industry. It further analyses the challenges of bullwhip effect from the perspective of electronically-enabled supply chain management (eSCM) systems and information sharing in the fast moving consumer goods (FMCG) industry. The study finds that information sharing is related to supply chain performance targets in the FMCG industry in terms of a higher order fulfillment rate and achieving shorter order cycle time through integrated e-SCM systems. The managerial implications of this study are that integrated IT infrastructure capability and top management support (in terms of visible involvement, commitment and participation of executives and the allocation of the necessary resources) are significant antecedents of the quality of shared information.
\end{abstract}

Keywords: Bullwhip effect, information sharing, information, visibility, velocity, volatility

\section{Introduction}

Supply chain relationships with suppliers and customers are impacted not only by the accuracy of information, but its availability, velocity and volatility (Wisner and Stanley, 2008). A number of scholars have provided empirical evidence on the role of information sharing in consumer goods retail supply chains, including the value of shared information on inventory (Cachon and Fisher, 2000), optimal inventory holding policies (Gavirneni, Kapuscinski and Tayur,1999), and centralized demand (Chen, 2003). These generic mitigation, simulation and modeling approaches were reviewed to examine the cascading supply chain bullwhip effect (Forrester (1958); Lee, Padmanabhan and Whang, 1997) and Balan, Vrat and Kumar, 2009). This study aims to understand the challenges of bullwhip effect and to ascertain whether supply chain information visibility (Barratt and Oke, 2007) quality, timeliness and access will improve supply chain responsiveness and frequencies of order replenishment capabilities (Mentzer, Soonhong and Bobbit, 2004; Patterson, Grimm and Corsi, 2003). From the macro perspective, Barratt and Barratt (2011:514) explored the specific roles of internal and external information-based linkages across the entire retail supply chain in reducing uncertainty and demand order variability. The degree to which supply chain partners have on-hand information relating to demand and supply for planning and control management was attributed to supply chain information visibility (Barratt and Oke, 2007).

Wang and Wei (2007:647) contend that the opportunistic behavior that results from information asymmetry strengthens asymmetric relationships (visibility fails to mitigate) in terms of the scope and depth of information. Information visibility in the retail supply chain mitigates bullwhip effect problems. Extant research studies note that a lack of information, restricted, private information and a paucity of lead time information exacerbate demand order variability. Under these circumstances, the downstream sites of the supply chain rely on the history of order arrivals to make replenishment decisions (Cheng and $\mathrm{Wu}, 2005)$ while the upstream sites are denied information on product availability downstream and employ a silo-oriented new product roll-out strategy (Ferguson and Ketzenberg, 2006; Li and Gao, 2008). Although superficial levels of collaboration, inevitable conflicts between supply chain partners (suppliers and retailers) (McIvor and Humphreys, 2002; Emiliani, 2003) and a lack of trust in information sharing can result in supply chain partners opting to go it alone, "willingness to negotiate functional transfer, share key information and participation in joint operational planning" can address problems relating to demand variability (Sheu, Yen and Chae, 2006). This study implicitly avoids being overzealous in terms of semantics in interpreting the concept of trust; rather than regarding trust as unconditional (Davies, 
2006), it recognizes that trust in sharing information arises from the need to reduce uncertainty through collaboration and the integration of organizational activities.

Problem statement and research objectives: Extant studies and the brief background provided in the previous section form the basis for the thematic framework that gives rise to the problem statement. This study investigates amplified consumer demand order variability (DoV) in the FMCG industry as orders cascade from downstream (retailers) to the midstream and upstream (distribution centers, manufacturers as capacitated suppliers, and lead suppliers and $n$-tiers) sites of the supply chain network. While FMCG businesses show stable consumer demand for most consumer items, the study focuses on understanding the dynamics of less certainty in supply and volatility in demand orders for fast moving consumer items. Hence demand on node-to-node (distributor, wholesale, manufacturer, lead supplier, even $n$-tiers) levels varies due to the cascade effect. Simchi-Levi, Kaminsky and Simchi-Levi (2008) concluded that the variability in orders emanating from the downstream site to the upstream site is more apically distended than the variability in quasi-stable real consumer demand in the form of magnified oscillations upstream. The study aims:

- To analyze the challenges of bullwhip effect from the perspective of e-SCM systems and information sharing in the FMCG industry.

- To examine the relative magnitude of advance economic information sharing in optimizing integrated supply chain activities in the consumer goods industry.

\section{Literature Review}

Defining Bullwhip Effect: The fundamental challenge for the FMCG industry is to predict uncertainty in consumer demand. Although the bullwhip effect on both stream sites of the supply chain indicates uneven variance amplification, researchers have used robust diagnostic tests to detect the existence of bullwhip effect. According to Ouyang and Daganzo (2006:1544), the variance amplification evades the early stages (retailers) but it intensifies in the upstream sites (capacitated suppliers) along the operating policies. Robust stability analysis in the multi-stage chain stabilizes the supply chain network with operating strategies (Ouyang and Li, 2010), and chains with stochastic supplier behavior and operating uncertainties (Boccadoro, Martinelli and Viligi, 2006; Ouyang and Daganzo, 2008). The impact of orders from multiple node-to-node information sharing networks affects each supplier's ordering decision; Ouyang and Li, (2010:799) attributed this distortion and order variability from multiple participants at different levels of the supply chain network to the degree of relationships, coordination and collaboration among the trading supply chain members.

The literature on bullwhip effect has extensively discussed the effect of this phenomenon, its reduction, simulating the system's behavior and experimental validity. Ouyang (2007:1107) refers to the bullwhip effect as "a phenomenon in supply chain operations where the fluctuations in the order sequence are usually greater upstream than downstream of a chain". In terms of supply chain management as a dynamic decision task, Croson, Donohue, Katok and Sterman (2005) indicate that in the absence of quality performance, risk coordination, collaboration and stability in the multi-node process, decisions are taken independently by supply chain trading members. The preceding section outlined the conceptual framework within the parameters of two constructs (bullwhip effect and information sharing) underlying industry practices and extant research studies. Wu and Katok (2006:839-850) define the bullwhip effect as "the observation that the variability of orders in supply chains increases as one moves closer to the source of production". This situation is epitomized by unstable and unpredictable demand for the end product where the retail orders placed with the distributors can exhibit a high degree of variability. The orders the distributors place with the manufacturer can have even higher variability (Davis and Heineke, 2005; Chopra and Meindl, 2007). The phenomenon moves all parties in the supply chain away from the efficient frontier and results in a decrease in both customer service satisfaction levels and profitability within the supply chain. Christopher (2011:3) notes that supply chain management is the network of mutually connected and interdependent organizational linkages that involve, "the management of upstream and downstream relationships with suppliers and customers in order to deliver superior customer value at less cost to the supply chain as a whole". A supply chain network should be comprised of cross-functional and extended cross-enterprises that coordinate integrated activities from lead suppliers to the ultimate consumption cycle stage in order to absorb the magnitude of bullwhip effect.

Supply Chain Information Sharing Perspective: Several studies have debated the difference between knowledge sharing (tacit, which is difficult to codify, transmit or convey within a specific context and 
explicit, with discrete and digital systematic means for decision making) and information sharing (obligatory and template-based in terms of order exchange, and strategic, operational and competitive information sharing) in improving supply chain business performance. This literature review focuses on the dimensions of information sharing such as quality, velocity, volatility and electronic integration, relative to the challenges of bullwhip effect in the FMCG industry. Information velocity is a term used to describe how fast information flows from one process to another, while information volatility describes the uncertainty associated with information content, format, or timing, that must be properly handled to add value to the supply chain. According to Li and Lin (2006:1641), the quality of shared information refers to the "quality of information shared among supply chain partners as this quality includes aspects such as information usefulness, information accuracy and information accessibility".

Different information management strategies are required to manage different types of products, especially in the presence of supply chain risks and order variation on the upstream side. Fisher (1997:105-116) classified consumer products as fashion (innovative) products or functional products. Paton, Clegg, Hsuan and Pilkington, (2011:257) stress that "supply chain for innovative products should have supply chain market-responsive while functional products require efficient and stable supply chains to retain high utilization rated of manufacturing". While supply chain operations efficiency is concerned with activities that improve supply chain performance benefits, Barratt and Oke (2007:1217) note that, supply chain visibility is the extent to which partners within a supply chain have access to and share information which partners consider useful to their supply chain's operations efficiency and mutual performance. According to Barratt and Barratt (2011:515), meaningful supply chain operational benefits depend on critical information sharing outcomes in terms of the quality, timeliness and usefulness of the information in creating visibility. The authors observe that the benefits include "the information performance benefits that arise from visibility such as improved market-responsiveness process improved planning, improved frequent replenishment capabilities and improved active communication decision-making process".

Framework of Information Sharing: Information sharing is closely linked with active supply chain communication and coordination to mitigate the challenges of consumer order demand variability. Chen (2003:341) presents a comparative analysis on downstream-demand-side information (sales information or inventory status at point of sales), and upstream-supply-side information, such as lead time cycle, new product introduction, and plant operations. The total information flow cycle in the network should epitomize balanced congruence in sharing critical upstream, midstream and downstream information with supply chain members on the design and rollover of the product, product availability, distribution capabilities and product shelf-availability. Upstream information sharing visibility should improve overall supply chain performance outcomes and eventually benefit channel partners of supply chain entities. Li and Gao (2008:522-531) maintain that, in an information sharing model, the upstream manufacturer has no incentive to mislead midstream and downstream partners about new product information. Choudhury, Agarwal, Singh and Bandyopadhyay, (2008:117-127) tested supply chain performance benefits resulting from increased sharing of quasi-real-time information (sharing demand and inventory information) among players and observed that the potential benefit of information sharing between channel members increases as the supplier's capacity increases and the allocation of inventory by suppliers to retailers improves.

This implies that inventory allocation among supply chain channel partners that share underlying realtime information results in improved coordination between supply chain processes, reduces costs and ameliorates consumer demand order variability (Choudhury et al., 2008; Barratt and Barratt, 2011). A number of studies have outlined the advantages of sharing information in supply chain management. Firstly, information sharing leads to 'high levels of supply chain integration' (Jarrell, 1998:58) by enabling organizations to make dependable deliveries and enhance product clock speed; secondly, quality information sharing contributes positively to supply chain performance, customer service satisfaction levels (Spekman, Kamauff and Myhr, 1998) and the quality of partnerships (Lee and Kim, 1999; Zhao, Xie and Zhang, 2002); and thirdly, Li, Huang and Lin, (2002) assert that the higher levels of information sharing are associated with lower total costs, higher order fulfillment rates and shorter order cycle times. Li and Lin (2006:1641) further note that quality information sharing may be influenced by contextual factors, such as the type of industry, firm size, a firm's position in the supply chain, supply chain length, and the type of supply chain. Organizations with high levels of quality information are associated with low levels of environmental uncertainty, high levels of top management support and information technology (IT) enablers to entrench product clock speed. The proper mapping of quality information 
flows should allow managers to better identify how information is transmitted from one point to another both within the firm and across extended enterprises, including lead suppliers and customers.

Information flow mapping: Flow maps serve as a basis to analyze information needs and the services necessary to align the firm's information collection and transfer capabilities with the information needs of its internal and external users (Wisner and Stanley, 2008:316). The value of information as an intellectual asset that captures, transforms and exchanges information should entrench a flow mapping paradigm along with the interplay between the corporate information flow (flow from the firm to its customers), environmental information flow (customers to the firm) and internal information flow (flow within the firm). Information velocity is a term used to describe how fast information flows from one process to another, while information volatility is the uncertainty associated with information content, format, or timing that must be handled to add value to the supply chain (Wisner and Stanley, 2008; Simchi-Levi et al., 2008). Wisner and Stanley (2008:316) further consider enabling information technologies as a replacement for human coordination, to reduce uncertainty, promote new coordination structures and substitute information and knowledge for inventory.

Supply chain partners require accurate real-time information on current inventory levels, order and delivery status, production and forecast changes, and the latest product design changes. Durugbo, Hutabarat, Tiwariand and Alcock (2011:1) stress that the flow, deployment or delivery of goods in modern supply chains and businesses is characterized by the concurrent flow of information for improved customer service levels through exchanging information between customers, updated progress of orders and sales teams (Childerhouse, Hermiz, Mason-Jones, Popp, and Towill, 2003; Iskanius, Helaakoski, Alaruikka, and Kipina, 2004). A research study by Myhr and Spekman (2005:179-186) revealed that "electronically mediated exchange is a more salient determinant of collaboration in supply chain relationships involving exchanges of standardized products while trust is more of a factor in achieving collaboration in exchanges involving customized products". It appears that trust establishes a base-line level of collaboration that is enhanced and reinforced through the use of electronically mediated exchange. While Morgan and Hunt (1994:20-38) argue that 'constant communication is essential to help foster and build trust, Myhr and Spekman (2005:179) maintain that through constant interaction and information sharing via electronically mediated exchange', partners experience a closer bond and this serves to re-enforce trust that contributes to collaboration. The business world is composed of a network of interdependent relationships within a collaborative paradigm that presents opportunities to share advanced economic information such as demand forecasting and product life cycle planning. Wisner and Stanley (2008:212) advocate "close supply chain collaborative relationships with customers and suppliers on frequent active communications that add real-time information visibility to supply chains and mitigate the phenomenon of bullwhip effect and reduce safety stock problems".

Rinehart, Eckert, Handfield, Page, and Atkin, (2004:25-43) classify such relationships into market governed situations, relationally governed systems, and ownership governed systems. Successful relationships for sharing real-time information in supply chains are distinguished by attributes including trust, interaction frequency, and commitment. Such close relationships mean that "channel participants share risks and rewards and are oriented for long-term relationship" (Kotabe, Martin, and Domoto, 2003:293). Moreover, Chen, Paulraj and Lado (2004:333) note that a long-term relationship infers that "the supplier will become part of a well-managed chain as a lasting continuous effect on the competitiveness of the entire supply chain network". The establishment of trustworthy relationships across supply chain networks should be an impetus to share accurate information and establish effective and efficient supply chain management practices. If well-managed, a reduction in system-wide costs can be achieved, as well as increased customer satisfaction.

Value of information sharing: Information flow across supply chain networks is perhaps the most crucial process for firms seeking to proactively manage their supply chains. In terms of information flow direction, inventory information sharing and production plan information sharing is a two-way communication between the downstream and upstream organizations in the supply chain. Gavirneni et al. (1999), Cachon and Fisher (2000) and Moinzadeh (2002) focus on how information can be used to improve supply chain performance and the conditions in which information is most valuable. Chen and Yu (2005:144) consider cases where information such as available supplier capacity and lead time is shared forward in the supply chain in order to reduce supply uncertainty on the part of customers, while Ferguson and Ketzenburg (2006:57-73) address the value of a supplier sharing the age of its inventory with a retailer to improve replenishment decisions for a perishable product. The degree of visibility, 
transparency and synchronization requires a high level of process alignment, which in itself demands higher levels of collaboration. The supply chain process needs to be linked on both stream sites to lay the foundation for supply chain synchronization based on the value-added exchange of information between the extended enterprise and virtual enterprise as a series of relationships among supply chain partners (Christopher, 2011). Ng, Piplani, and Viswanathan, (2003:449-457) developed three scenarios of information exchange: echelon demand history, end-user demand, and downstream order schedule. In assessing the value of information sharing for a particular supply chain operating under different combinations of system parameters, the decision maker has to assess several performance measures simultaneously and determine the value of information sharing for a particular combination of parameters.

Information sharing and trust in supply chain relationships: A successful supply chain requires an effective, integrated supply chain planning network that is based on shared information and a meritorious degree of trust among partners. According to Kwon and Suh, 2004:4) a firm's trust in its supply chain partners is highly and positively related to perceived satisfaction; the partners' reputation in the market and communication, while Chu and Fang (2006:224) claim that a perceived conflict of interests has a strong negative impact on trust. Anderson and Narus (1990:45) refer to trust as a "firm's belief in another company"; the action arising from such trust should result in positive supply chain outcomes for integrated networks as well the avoidance of unexpected actions that result in negative outcomes. Morgan and Hunt (1994:20-38) define trust as “a firm's belief in its partner's trustworthiness and integrity while commitment is interpreted as an exchange partner believing that an ongoing relationship with another is so important as to warrant maximum efforts at maintaining it by expressing an enduring desire to maintain a valued relationship". Trust and commitment result in "greater openness between trading supply chain partners and much information sharing and as a result greater knowledge for each other's contribution to the relationship"; open information sharing and continuous inter- and intra-improvements are requirements for successful collaboration ( $\mathrm{Li}$ and Lin, 2006; Dong, Xu and Dresner, 2007; Wu and Chuang, 2009).

Gounaris (2005:126) stresses that "both trust and commitment should stimulate a relational bond between the supplier and customer", which facilitates the establishment of productive collaborations. Gao, Sirgy and Bird, (2005:397) add that if suppliers demonstrate trust and commitment in their contracts, organizational buyers are likely to exhibit less uncertainty in their purchase decisions. These scholars (Gounaris, 2005; Gao et al., 2005) reach the same conclusion as Morgan and Hunt (1994), that when commitment and trust exist simultaneously they may enhance the efficiency, productiveness and effectiveness of a supply chain. Inter- and intra-organizational trustworthy relationships are characterized by commitment to an integrated supply chain network and mutually recognized and acknowledged collaboration (Daugherty, 2011:16). Visibility, transparency and synchronization require a high level of process alignment, which in itself demands higher levels of collaboration. The guiding principle is willingness to share real-time information on future strategic initiatives with supply chain participants in order to collectively satisfy customer demands faster and more efficiently while reducing the risks relating to inventory positioning. According to Bowersox, Closs and Cooper (2013:17), "the information sharing paradigm should achieve a high degree of active cooperative behavior requirements to which supply chain participants voluntarily share operating information".

The scope of information sharing in cross-enterprise collaboration and joint strategic planning and the magnitude of extended enterprise integration should benchmark supply chain performance benefits on the degree of mutual trust and the quality of leadership. Van Weele (2010:394) suggests that "trust can be generated if company staff acts in a consistent and reliable manner while trustworthiness primarily stresses ethical principles and consistent organizational behavior and integrity". Supply chain integration and trust in information sharing are built on constructive, long-term relationships among trading supply chain partners. Bowersox et al. (2013:353-354) distinguish between dimensional forms of trust: "Reliability-based trust is grounded in an organizational perception of the potential partner's actual behavior and operating performance where the partner is willing to perform and capable of performing as promised under trustworthy relationships. While character-based is based in an organization's culture, leadership and philosophy considering the action's impact on the other". Mutual acts of fairness and equitability would mitigate silo-oriented behavior among the supply chain partners to ameliorate the impact of bullwhip effect. Heikkila (2002:747) recommends "the dependence of one company on a partner that refers to the firm's need to maintain a relationship with a partner in order to achieve mutual goals", while Bowersox et al. (2013:354) interpret this relationship as the partner's willingness and 
capability to perform as promised in supply chain collaborative relationships. Furthermore, Sheu et al. (2006:24) highlight that high levels of interdependence motivate willingness to negotiate functional transfer, share key information, and participate in joint operational planning.

While the continuous, seamless collaboration and integration of organizations should lead to higher levels of trust, Davies (2006:24) interprets trust as a reduction of uncertainty that is useful in understanding collaborative relationships. As an altruistic, unconditional concept, trust is not particularly helpful in a business context. These close relationships, anchored in trust, commitment and loyalty between supply chain partners, ensure the adoption of joint initiatives to maximize the flexibility of the supply chain as a whole (Chang, Lin, Chen, and Huang, 2005:1115-1132). Komiak and Benbasat (2004:181-207), and Paul and McDaniel (2004:183-227) identify four types of trust that have the most potential to explain organizational-level performance impacts and coordination differences within supply chain relationships: calculative trust, competence trust, trust in integrity and trust in predictability. "Competence trust develops when the skills needed to perform a task reside across partners, and the level of search is undertaken by one party, for those skills before selecting the right partner to enter into such a relationship (Heffernon, 2004). Integrity is based on experience from interpersonal relationships between the trustee and the trust or and more specifically on their perceptions of each other's past behavior. Integrity is important in a supply chain because of the presence of numerous players with sometimes conflicting goals and the existence of written and oral promises to be fulfilled (Komiak and Benbasat, 2004; Ghosh and Fedorowics, 2008). Predictability reflects the trustor's belief that a trustee's actions (good or bad) are consistent enough that it can be forecasted in a given situation. It is based on the premise that organizations are consistent, stable, and predictable in relation to past patterns of behavior". According to Komiak and Benbasat (2004:205), relationship development explained by this type of trust "depends on an ability to predict outcomes with a high probability of success, which is a key to the effective and uninterrupted operation of a supply chain". Although the relationships among supply chain participants differ in their intensity and the extent of real collaboration, building trust in the form of full and frank sharing of information is necessary for the effective functioning of the relationship (Bowersox et al., 2013:354). Thus, greater relationship commitment exists in supply chain relationships when leaders exercise power, leadership and cooperation in the form of rewards and expertise to manage conflict and risk in the trustworthy relationship (Van Weel, 2010; Bowersox et al., 2013).

\section{Methodology}

Research design: The research design outlines a plan and structural framework for how the researcher intends to conduct the study to solve the research problem (Cooper and Schindler, 2008:140). The overall research design was an exploratory survey on the empirical research design framework that constituted the blueprint for the data sources, data collection, data sampling methods and measurement, and statistical analysis of data. This design represented the plan and structure of the investigation to obtain answers to the research questions on bullwhip effect and information sharing. Kerlinger (1986:279) cited in Blumberg, Cooper and Schindler (2008:195) notes that, "a research design expresses both the structure of the research problem and the plan of investigation used to obtain empirical evidence on relation of the problem". This study employed a cross-sectional quantitative approach (that is, measurements were taken at one point in time on numerical exploration) to analyze data, and a selfadministered questionnaire survey instrument was used for data collection. Organizations in retail sales, logistics, warehousing, marketing, manufacturing and information technology hubs were the units of analysis in this study, and managers (senior and functional levels) including supervisory level (nonmanagerial) were the subjects within the organizations.

Survey Instruments: A survey instrument incorporating a list of cases from bullwhip effect and information sharing was constructed based on the literature reviewed. A self-developed survey instrument was designed based on the constructs of the conceptual framework using a structured questionnaire to achieve the research objectivities. While it could be argued that objective scales are more insightful, the study uses subjective scales due to the multi-sectorial nature of the survey. Sekaran and Bougie (2009:197) describe a questionnaire as an efficient data collection mechanism with a preformulated, written set of questions to which respondents record their answers, usually within rather closely defined alternatives. The pre-formulated thematic instrument (bullwhip effect and information sharing) was grounded within the extant literature review and was pre-tested using key industry practitioners and discipline-based academics for suitability to enhance face and content validity. 
The survey questionnaire was structured into five sections with section one including typical demographic, personal profile and general information for both the company and individual respondents; representing nominal data (mutually exclusive and collectively exhaustive) and rank-ordered statements (ordinal data). Section two included dichotomous questions (Yes or No) on general perceptions of inventory management systems to mitigate bullwhip effect, representing nominal data. Sections three and four included interval data with a series of statements that covered operational supply chain networks on bullwhip effect, information sharing, electronic supply chain management integration and global optimization strategies to ameliorate bullwhip effect. According to Anderson (2009:312), clarity about the research questions and types of data collected should allow the researcher to identify the most appropriate quantitative data analysis tools to use on the main underlying option for parametric and/or non-parametric data (Collis and Hussey, 2009; Cooper and Schindler, 2008; Davies, 2007; Hair, Babin, Money and Samouel, 2003). The last section listed numerous e-SCM systems that were being used or were recommended to some extent by the respondents. Respondents indicated their degree of agreement or disagreement with statements, with 5 representing "strongly agree" and 1 representing "strongly disagree". In other words, multi-question Likert-type five point scales ranging from strongly agree to neutral to strongly disagree in sections three and four of the questionnaires were used to derive composite scores of the data for each variable as representative of interval data. In accordance with the principles of ethical research the respondents were assured that the researcher will not disclose the names of participating firms or individual respondents to protect their confidentiality. A guarantee of anonymity tends to boost respondents' confidence and willingness to participate in a research study, especially when, as in this study, extensive questions on organizational practices are posed to staff occupying high-level positions.

Data sampling methods and measurement: Judgment sampling is a non-probability sample with purposive sampling that conformed to this study's criteria. Non-probability sampling has some compelling practical advantages (Blumberg, Cooper and Schindler, 2008:235). This sampling occurs when a researcher selects sample members to conform to some criterion (Cooper and Schindler, 2008: 397). It calls for special efforts to locate and gain access to individuals that have the requisite information. Referral sampling proved to be the most efficient and effective approach that eventually yielded the majority of the potential respondents on the sampling frame. Snowball sampling relies on approaching a few individuals from the relevant population and these individuals then act as informants and identify other members from the same population for inclusion in the sample (Welman, Kruger and Mitchell, 2005:69).

The retailers (downstream supply chain) and capacitated suppliers (mid and upstream supply chain) in the selected FMCG industry constituted the population of 800 proportionate representatives within five major retail chain stores in eThekwini Metro, South Africa and approximately 300 suppliers for these retail groups in food (dairy, frozen, canned and general), beverages (hot and cold), and personal health care were considered for this empirical research study. The sample size of 456 (260 retailers and 196 suppliers) was considered adequate, as Sekaran (2003:295) notes that sample sizes of larger than 30 and less than 500 are appropriate for most research on a population-to-sample size table. In line with Sekaran (2003:294) and Bartlett, Kotrlik and Higgins (2001:48), the minimum returned sample size with a representative population size of 800 (retailers) and 300 (suppliers) is 260 and 196, respectively with an alpha of 0.05 and a degree of accuracy of 0.05 . The alpha value or level of significance (0.05) would become enshrined as the threshold value for declaring statistical significance in this study. This study has produced a sample size of 448 respondents with return rate of 98\% [(448/456) 100]. According to Krejcie and Morgan (1970), researchers typically set a sample size level of about 500 to optimally estimate a single population parameter; in turn, this will construct a 95\% confidence interval with a margin of error of about $\pm 4.4 \%$ for large populations. In terms of an inverse relationship between sample size and the margin of error, smaller sample sizes will yield larger margins of error. A larger sample size generally leads to increased precision when estimating unknown parameters (Cooper and Schindler, 2008; Babbie and Mouton, 2001; Krejcie and Morgan, 1970).

Administering Survey: The questionnaires were self-administered where the scheduled delivery and collection on agreed time intervals in order to enhance the return rate. The questionnaires were delivered to individual gatekeepers to administer the survey within their domain and most were personally administered by the researcher within the eThekwini Metro, South Africa. The relevant letters (gatekeeper's letter, ethical clearance certificate, and consent letter to ensure confidentiality and 
anonymity) were shown to the gatekeepers each time the researcher was given permission to enter their domain.

\section{Results}

Discussion and Analysis of Data: The statistical analysis examined the study's research objectives and hypotheses. The summarized univariate technique examined the distribution of cases on one variable at a time using descriptive statistics (mean and standard deviation) and the bivariate technique used inferential statistics. Multivariate analysis as a statistical technique was organized around a scheme of dependence (regression analysis) procedure in order to develop models that best describe the population as a whole.

Figure 1: Positive factors that influence information sharing

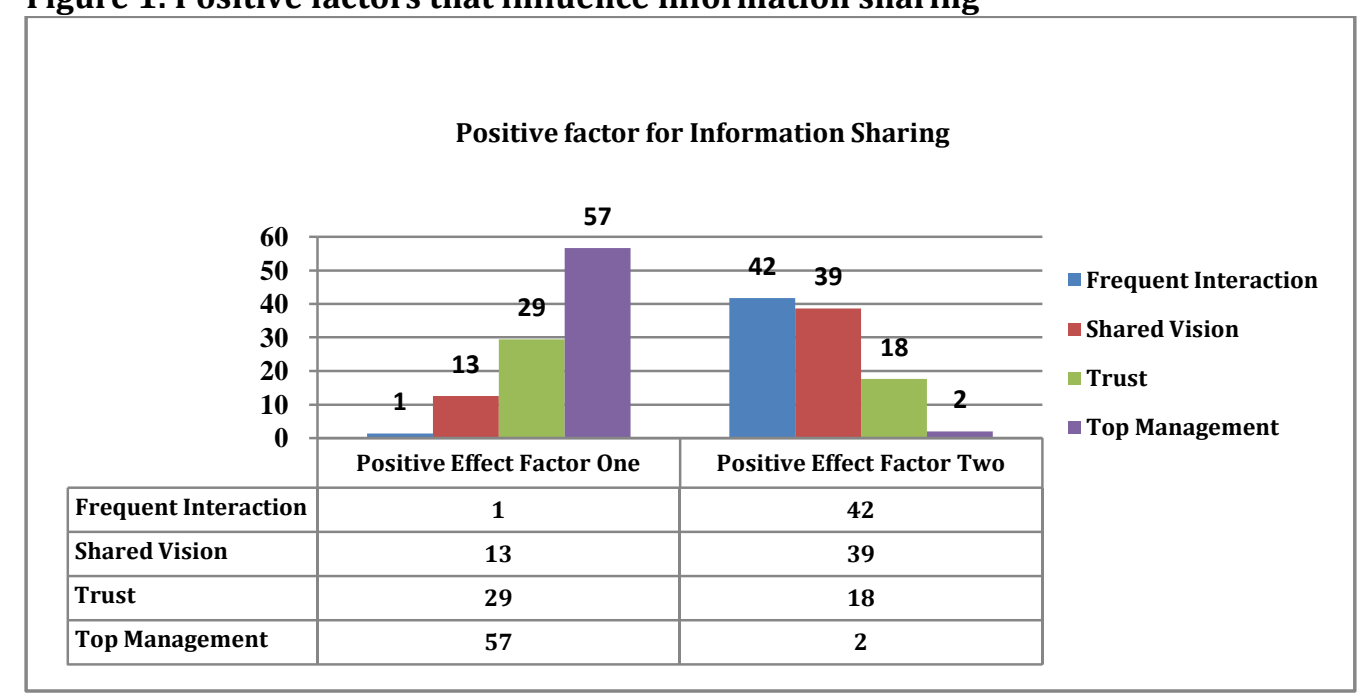

Information sharing is considered to offer reciprocal value between the downstream and upstream sites in the supply chain. However, rational and self-optimizing behavior by each of supply chain stages can hinder the sharing of demand order information. Among the four positive factors (top management, trust, shared vision and frequent interaction), $57 \%$ of the respondents indicated top management support and $42 \%$ frequent interaction between supply chain partners as the most critical factors that positively influence information sharing to mitigate bullwhip effect. Figure 1 further acknowledges trust among supply chain partners to share a common vision as a positive factor in mitigating bullwhip effect as orders moving up the supply chain network.

Cross-tabulating Managerial level and positive factors in information sharing: This study depicts differences in opinion by management level regarding the critical factors that positively influence information sharing among organizations. The table indicates that $76 \%$ of the combined middle and first level sample respondents felt that a shared vision and frequent interaction between supply chain partners positively influence information sharing. Although top management highlights frequent interaction with 29 counts, the non-managerial level (14) and middle level (36) recommend trust among supply chain partners as a critical factor to influence either emphatic or advanced economic information sharing. In the parlance of hypothetical assessment as the integral observation on these counts, there is a relationship between levels of management expert opinions and positive factors of information sharing.

Question Three: How do the managerial levels rank the positive factors that influence information sharing?

These positive factors in sharing information indicate a statistically significant relationship with the levels of management expert opinions. The respondents ranked a shared vision and frequent interaction between supply chain partners as positively influencing information sharing. Trust among the supply chain partners was also considered a critical factor to influence either emphatic or advanced economic information sharing. Vijayasarathy (2010:366) affirms that the level of trust in a supply chain partnership is indicative of how the member organizations perceive one another in terms of reliability and integrity to share quality information and their resolution to continue a long-term partnership. The timely and 
accurate flow of data with e-SCM technology facilitates the enhancement of real-time information exchange. If top management expertise underpins supply chain capabilities, top management should value and directly appropriate organizational responses to market changes and supply chain flexibility.

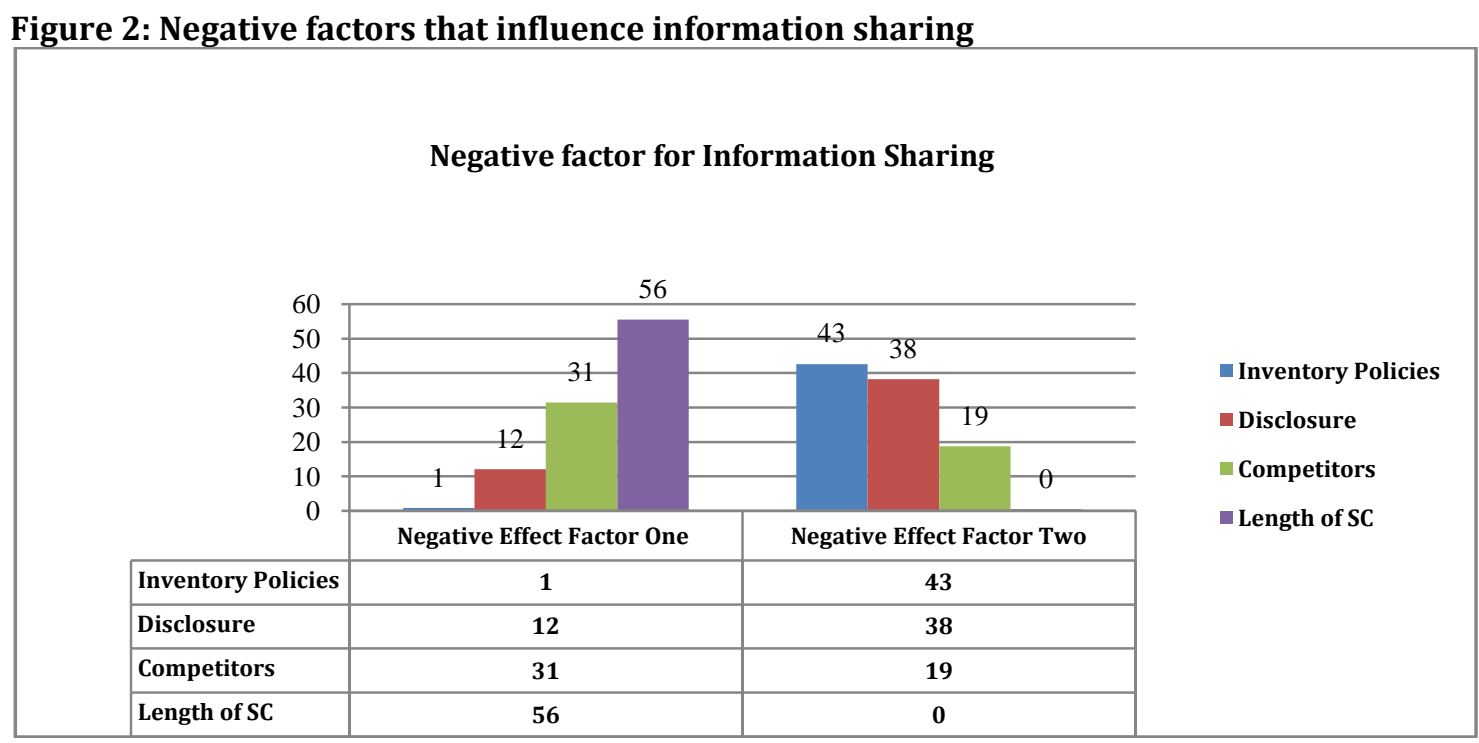

Figure 2 shows, that, $56 \%$ of the respondents regarded the length of the supply chain network as a negative factor influencing integrated information sharing. Although supply chain partners require accurate information on current inventory levels, effective information sharing as a source of competitive advantage is negatively influenced by inventory control policies (43\%) for both internal and external information flows and support throughout the supply chain. In terms of information visibility as a mitigating factor to make consumer demand data available throughout the chain, $31 \%$ of the respondents argued that information sharing can result in competitors accessing such information and $38 \%$ feared loss of power through disclosing information amongst the supply chain trading partners.

Cross-tabulating Managerial level and negative factors in information sharing: This study revealed a significant statistical association between the negatively amplified oscillation for information sharing travelling upstream the supply chain and the levels of managerial expert opinions. The first and middle levels of management indicated that the length of supply chain channel network coupled with the loss of power caused by competitors having access to advance economic information impede the degree of willingness to exchange data. The difference in inventory control policies creates a time-lag on the order replenishment process and first level management felt that this has a negative effect on real-time information sharing. These bivariate tests were carried out using hypothetical statements and exploratory refined research questions to investigate the major research objective.

Question: How do the managerial levels rank the negative factors that influence information sharing? This study identified the critical factors from extant research findings and examined the positive and negative influence on information sharing from an organizational perspective. The respondents' managerial level was cross-tabulated against the negative factors in information sharing. There was a statistically significant association between the negative factors for information sharing travelling upstream the supply chain and the levels of managerial expert opinions. 
Figure 3: Integrated electronic supply chain management systems and information sharing on bullwhip effect

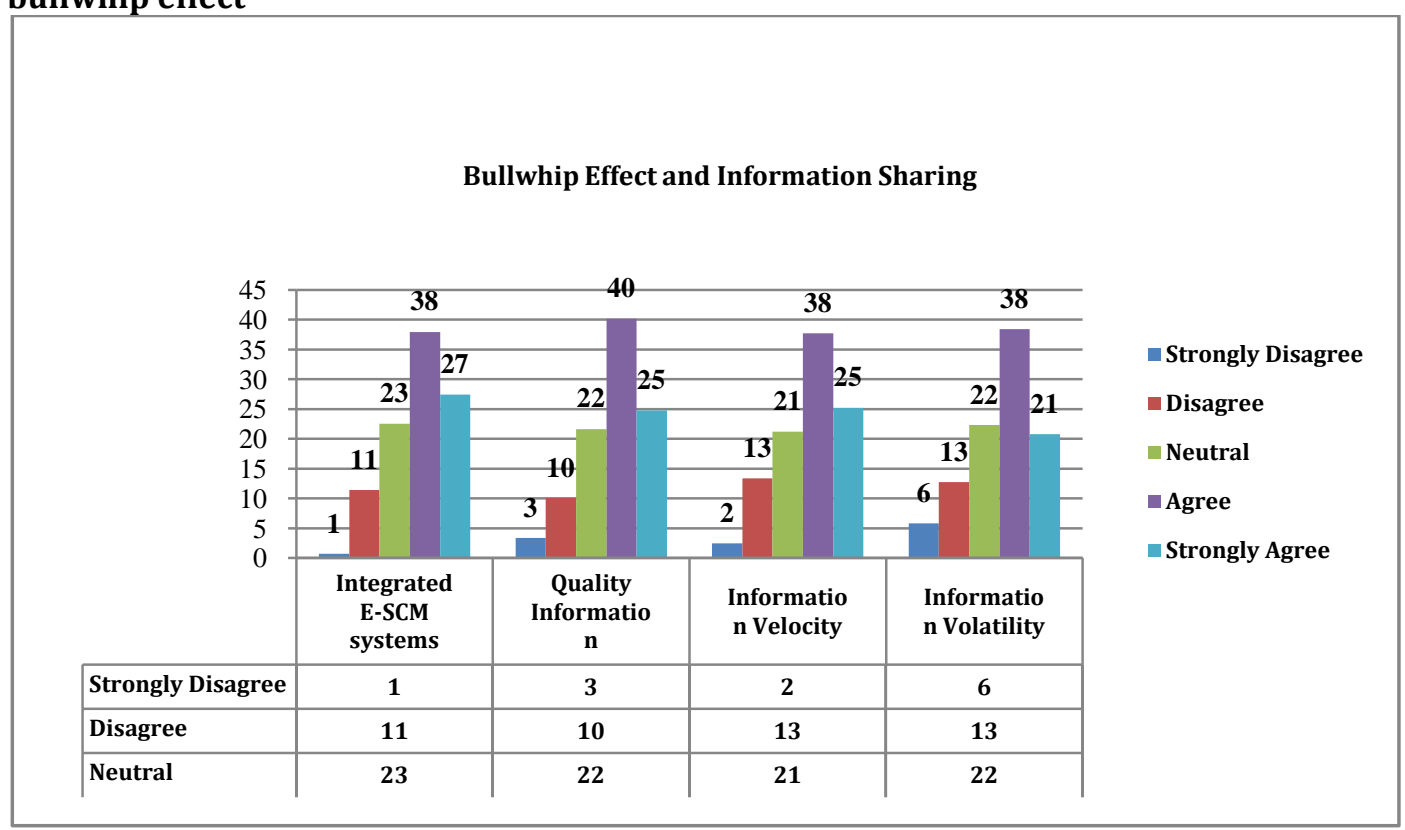

Although $65 \%$ of the respondents agreed that integrated e-SCM systems improve information sharing, it is confronted by a "certain level of environmental uncertainty, embattled top management support", and embroiled in incompatible information technology enablers. Fifty nine percent of the respondents concurred, that information volatility creates unstable demand, and supply uncertainty due to the nature, format and timing of information. Successful relationships for better information sharing are characterized by trust, frequent interaction and commitment. By the same token, $65 \%$ of the respondents highlighted the quality of information, while $63 \%$ agreed that the velocity of information sharing contributes positively to a higher order fulfillment rate and shorter order cycle time when there is trust and commitment among supply chain partners.

Descriptive statistics: Measures of dispersion and central tendency provide a summary indication of the distribution of cases and an average value by describing a single variable within the exploratory study.

Table 1: Descriptive Statistics on information sharing and electronic supply chain management

\begin{tabular}{|c|c|c|c|c|c|c|c|c|c|c|c|}
\hline Items & $\mathbf{N}$ & Mod & Min & Maxi & Mean & $\mathrm{SD} / \sigma$ & Skew & Kurt & Med & $\begin{array}{l}\text { Sigma } \\
\text { BWE }\end{array}$ & Alpha \\
\hline $\begin{array}{llll}\text { Electronic } & \mathrm{S} & \mathrm{C} & \mathrm{M} \\
\text { Systems. } & & & \\
\end{array}$ & 448 & 4.00 & 1.00 & 5.00 & 4.4554 & .8502 & -2.164 & 2.487 & 4.57 & .000 & .842 \\
\hline Updated Demand & & & & & & & & & & & \\
\hline Forecast & 448 & 4.00 & 1.00 & 5.00 & 4.0402 & .9958 & -1.050 & .627 & 4.20 & .000 & .833 \\
\hline Information Sharing & 448 & 4.00 & 1.00 & 5.00 & 3.9955 & .9623 & -.929 & .531 & 4.13 & .000 & .835 \\
\hline $\begin{array}{l}\text { Information Sharing } \\
\text { (I\&F) }\end{array}$ & 448 & 4.00 & 1.00 & 5.00 & 3.9241 & 1.100 & -1.002 & .295 & 4.13 & .623 & .833 \\
\hline $\begin{array}{l}\text { Strategic } \\
\text { Communication }\end{array}$ & 448 & 4.00 & 1.00 & 5.00 & 3.8772 & 1.085 & -.842 & .040 & 4.05 & .031 & .834 \\
\hline $\begin{array}{l}\text { Integrated } \quad \text { E-SCM } \\
\text { systems }\end{array}$ & 448 & 4.00 & 1.00 & 5.00 & 3.8013 & .9891 & -.471 & -.610 & 3.88 & .001 & .834 \\
\hline $\begin{array}{l}\text { Inflated Demand } \\
\text { Orders }\end{array}$ & 448 & 4.00 & 1.00 & 5.00 & 3.7701 & 1.031 & -.684 & -.052 & 3.87 & .003 & .838 \\
\hline Quality Information & 448 & 4.00 & 1.00 & 5.00 & 3.7299 & 1.047 & -.675 & -.093 & 3.83 & .294 & .832 \\
\hline Information Velocity & 448 & 4.00 & 1.00 & 5.00 & 3.6987 & 1.064 & -.539 & -.491 & 3.80 & .127 & .832 \\
\hline Total Lead Time & 448 & 4.00 & 1.00 & 5.00 & 3.6696 & 1.041 & -.630 & -.117 & 3.76 & .794 & .834 \\
\hline $\begin{array}{l}\text { Economic } \\
\text { Information }\end{array}$ & 448 & 4.00 & 1.00 & 5.00 & 3.6585 & 1.147 & -.651 & -.327 & 3.79 & .065 & .831 \\
\hline $\begin{array}{l}\text { Inventory } \\
\text { Positioning }\end{array}$ & 448 & 4.00 & 1.00 & 5.00 & 3.6540 & 1.098 & -.645 & -.354 & 3.78 & .006 & .834 \\
\hline Mutual dependency & 448 & 4.00 & 1.00 & 5.00 & 3.6250 & 1.085 & -.550 & -.413 & 3.72 & .068 & .832 \\
\hline
\end{tabular}




\begin{tabular}{|c|c|c|c|c|c|c|c|c|c|c|c|}
\hline Flexible Response & 448 & 4.00 & 1.00 & 5.00 & 3.6071 & 1.174 & -.637 & -.485 & 3.76 & .006 & .830 \\
\hline $\begin{array}{l}\text { Confidential } \\
\text { Information }\end{array}$ & 448 & 4.00 & 1.00 & 5.00 & 3.6049 & 1.144 & -.471 & -.707 & 3.71 & .318 & .832 \\
\hline $\begin{array}{l}\text { Information } \\
\text { Volatility }\end{array}$ & 448 & 4.00 & 1.00 & 5.00 & 3.5558 & 1.125 & -.584 & -.390 & 3.67 & .914 & .833 \\
\hline Valid Total & 448 & & & & 79.2478 & & & & & & .840 \\
\hline
\end{tabular}

The respondents advocated that e-SCM systems $(M=4.56)$ are the most significant systems and that electronically-enabled supply chain management underpins effective updated demand forecasts $(\mathrm{M}=$ 4.04 with 0.996 standard deviation) where organizations jointly participate in updating the demand forecast across the stream sites of supply chain. Although e-SCM systems are significant in improving flexibility, future strategic communication $(\mathrm{M}=3.88)$ and informal and formal information sharing $(\mathrm{M}=$ 3.92) in a dynamic market, as well as information exchange $(M=4.00)$ are associated with high order fulfillment rates and shorter order cycle time to enhance supply chain performance targets in the FMCG industry. The respondents agreed that information volatility $(\mathrm{M}=3.56)$ creates unstable demand and supply uncertainty due to the nature, format and timing of information. Only the quality of information $(\mathrm{M}=3.73$ with 1.047 standard deviation) and the magnitude of information velocity $(\mathrm{M}=3.70$ with 1.064 standard deviation) enable organizations to produce dependable delivery and contribute positively to customer satisfaction and the service level of supply chain performance.

Integrated e-SCM systems $(M=3.80)$ provide flexibility to respond $(M=3.61)$ to emergency demand order changes despite the frequent practice of organizations constantly hold a large inventory to avert inventory stock outs $(M=3.68)$. The respondents agreed that e-SCM systems play a significant role (highly ranked $\mathrm{M}=4.46$ ) in improving willingness to share sensitive and confidential information ( $M=$ 3.60) based on trust, and offer greater control and access to advance economic information $(\mathrm{M}=3.66)$. Furthermore, these systems enhance profitability $(\mathrm{M}=3.70)$ and establish common goals and mutual dependency $(M=3.63)$ between collaborating supply chain partners to further optimize inventory positioning $(M=3.65)$ with a significant reduction in lead times $(M=3.75)$. Organizations tend to order large quantities to take advantage of transport discounts $(\mathrm{M}=3.85)$ despite a concerted effort to reduce total lead time $(\mathrm{M}=3.67)$ in terms of material, information and delivery lead times and delays. Normally, the mean seems to encounter / cross words with outliers (force the value on the mean upward or downward), but the median seems to comprise acceptable values in relation to mean values.

The median is the most appropriate locator of centre for ordinal data and has resistance of extreme scores (Cooper and Schindler, 2008: 438). The symmetric location on the same centre point of the average response, the middle value when the distribution is sorted from lowest to highest (median) and most frequently occurring value have distribution scores that cluster heavily or pile up in the centre with overall alpha values (0.840) on 448 sample size. The main objective of this study is to examine the role of e-SCM systems in enhancing efficient real-time information sharing and active coordination of supply chain processes to manage bullwhip effect. Organizations are jointly participating in updating demand forecasts across the stream sites of supply chains through e-SCM systems. Information sharing is an essential practice in supply chain management for forecasts, manufacturing schedules to achieve economies of scale; and the coordination of inventory replenishment frequencies to optimize deliveries and produce operational and financial business benefits (Chengular-Smith, Duchessi and Gil-Garcia, 2012:60). The respondents were further asked whether information sharing promotes supply chain coordination and eventually mitigates consumer demand order variability. Information exchange is associated with a high order fulfillment rate and a shorter order performance cycle time to enhance supply chain business performance targets in the FMCG industry. In contrast with the valuable business benefits of information sharing, information volatility creates unstable demand and supply uncertainty in terms of information context, format and timing.

E-SCM systems were valued for their ability to enable real-time information exchange to optimize flexibility, strengthen future strategic communication; and facilitate the exchange of informal and formal information in a dynamic market. These findings reflect electronic supply chain competencies that relate to prompt decision-making and commitment to flexible, strategic supply chain responses. According to Ngai, Chau and Chan (2011:235) cited in Shimizu and Hitt (2004), strategic flexibility is "the competence to identify changes in the environment, commit resources quickly to new courses of action in response to change, and recognize and act promptly when it is time to halt or reverse such response commitments". In terms of the extent to which an organization is effectively using electronic supply chain tools to manage information, the respondents agreed that quality information and the magnitude of information velocity 
enable organizations to produce dependable delivery and thus promote customer satisfaction, an enhanced level of supply chain performance and product availability. However, supply chain functionality and information technology systems are challenged by the magnitude of supply chain network linkages relating to inter- and intra-organizational processes

Multiple Regression Analysis: Cohen, Cohen, West, and Aiken, (2003) describe multiple regression as a flexible method of data analysis that may be appropriate whenever a quantitative criterion variable is to be examined in relation to any other factors expressed as predictor variables. This multivariate method manifests the clarity of tests of regression coefficients, and efficiency of winnowing out uninformative predictors (less predictive power in the form of interactions) in reducing a full model to a satisfactorily reduced model. Darlington (1999) points out that the products and squares of raw / original predictors in a multiple regression analysis are often highly correlated with each other, with a propensity to exhibit multicollinearity. Multicollinearity is a statistical phenomenon in which two or more predictor variables in the multiple regression model are highly correlated and provide redundant information about the response; as a result, the standard errors of estimates of the $\beta$ 's increase and simultaneously indicate decreased reliability. What is the best way to predict the phenomenon of bullwhip effect on information sharing from the sub-dimensions of information sharing? Correlation and multiple regression analyses were conducted to examine the relationship between information sharing and various potential predictors. The Pearson correlation test has been used to describe the degree of linear association between the variables. This study presents the correlation matrix to estimate the relationship between all possible pairs of variables using significance level of alpha $=0.05$. The significance level shows how likely it is that the correlations reported may be due to chance in the form of random sampling error. A correlation matrix provides details of acceptable positive correlation values between each pair of variables with significance less than 0.05 , and there are no strong correlations (range between 0.3 and 0.5 ) between the criterion and the predictor variables. The stepwise procedure entered two predictors (quality information and integrated e-SCM systems) and none were removed after two models.

Table 2: Statistics on Mode, ANOVA, Coefficients and Residuals

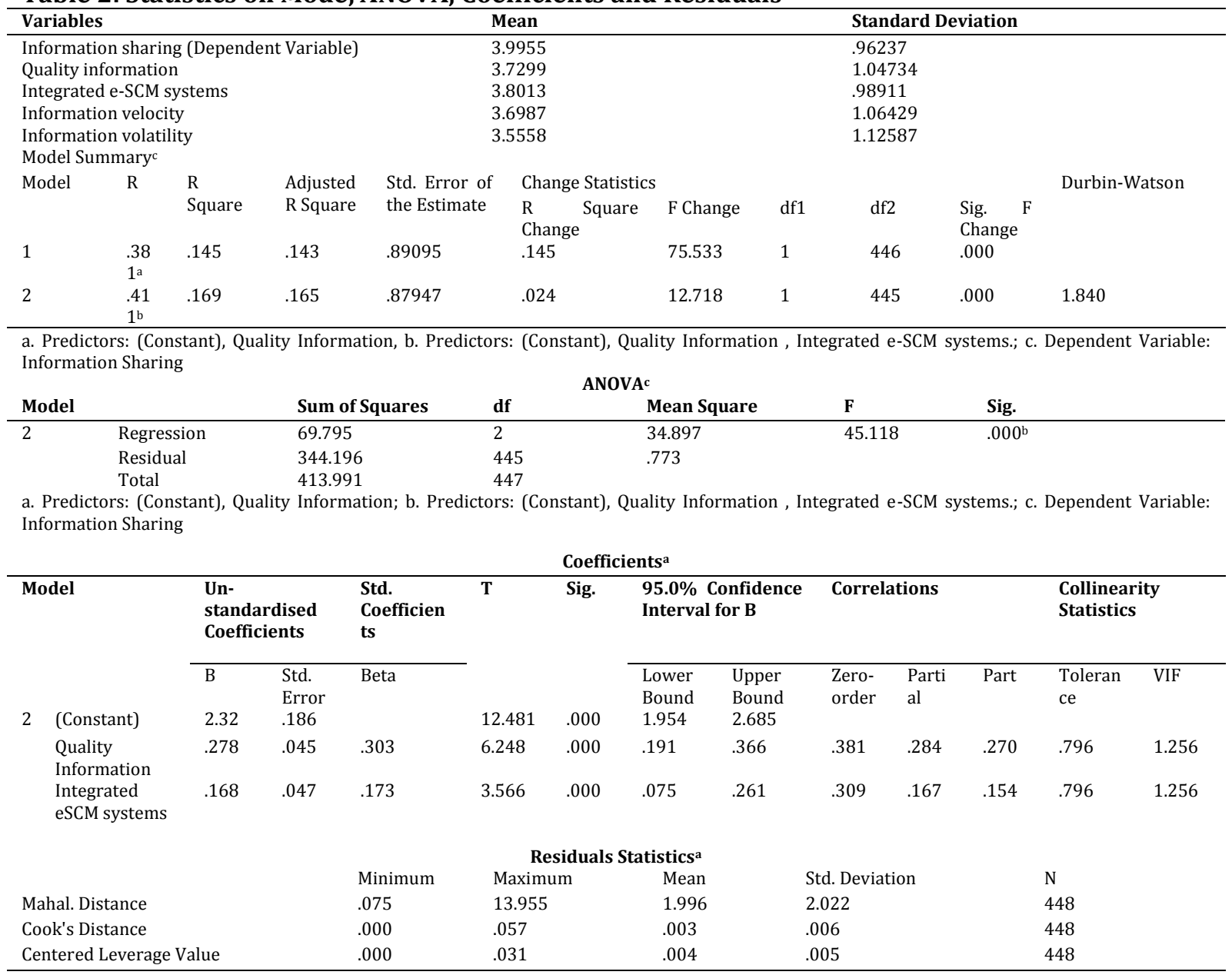


Leverage measures how much an observation influences regression coefficients. A rule of thumb is that leverage goes from 0 to 1 , while a value closer to 1 or 0.5 may indicate problems (Hamilton, 2006:175). Alternatively, leverage (hat element/value) greater than $3 \mathrm{p} / \mathrm{n}$ should be carefully examined as a useful rule of thumb for quickly identifying subjects which are very different from the rest of the sample on the set of predictors (Stevens, 2002). This study reveals accepted hat elements that lie between 0 (no influence on the model) and 1 (completely determines the model) ( $\min =0.000$ and $\max =0.031$ ). Mahalanobis distance is the rescaled measure of leverage [ $\mathrm{m}=$ leverage $\mathrm{x}(\mathrm{N}-1)]$, and the higher levels indicate higher distance from average values (Baum, 2006; Hamilton, 2006). Mahalanobis distance is the distance measured by P.C. Mahalanobis as an underlying correlation between variables by which different patterns can be identified and analyzed (Mahalanobis, 1936: 49-55). It looks at how far the case is from the centroid of all cases for the predictor variables. It is further associated with those points whose Cook distance are $>1$ (Tabachnick and Fidell, 2007) to determine which outliers are influential data points (Cook values have $\min =0.000$ and $\max =0.057$, less than 1 and no effect on the regression analysis). The higher the Mahalanobis distance for a case, the more that case's values on independent variables diverge from average values.

This objective on relative magnitude used multiple regression analysis to examine the relationship between information sharing (DV) and various potential predictors on the perspective of the phenomenon of bullwhip effect. Shih, Hsu, Zhu, and Balasubramanian, (2012:72) define information sharing as "the information need for supply chain efficient operation available at the right place and time to improve supply chain performance in a stable consumer demand". This indicates the challenges of bullwhip effect, multiple dyadic configurations and privacy or security across supply chains. On the other hand, knowledge sharing focuses on sharing tacit and explicit knowledge with high value information that may be useful in making decisions and prompting actions in response to the challenges of constrainedbased planning, trust and co-competition. Shih et al. (2012:72) further describe tacit knowledge as "extremely difficult to codify, transmit or convey with specific content and solves problems that are intractable, complex and variable. And explicit knowledge is discrete and digital, and may be easily transmitted via formal and systematic means". This study focused on the challenges of bullwhip effect and acknowledged both contextual information and knowledge sharing to find effective solutions that promote the efficient, streamlined flow of supply chain information using IT.

The Pearson correlation showed a significant degree of linear association between the variables. It is therefore acceptable to examine how much variance in the dependent variable (information sharing) is explained by each independent variable using the stepwise procedure in multiple regression analysis. The final model (model 2) emerged from the stepwise analysis with only two predictor variables $\left(\mathrm{R}^{2}=0.169\right.$, adjusted $\mathrm{R}^{2}=0.165, F=45.118, d f=2 ; 45, p<0.05$ ), and the relationship between criterion and predictor variables was explained by $16.9 \%$ of the variance in information sharing. By the same token, the two dimensions of quality information $(\beta=0.303, p<0.05)$ and integrated e-SCM system $(\beta=0.173, p<0.05)$ were found to be considerably and statistically related with information sharing without any multicollinearity problem. The Durbin-Watson statistic value (1.840 within the consistent range of 1.5 and 2.5) produced acceptable value with no problems related to multicollinearity (Garson, 2012). There is no multicollinearity problem for this study; the variance inflation factors (VIF) are equal to 1 (or VIF $\leq$ 10 ), and tolerance scores are more than 0.20 or 0.10 ( $0^{\prime}$ Brien, 2007). Nevertheless, a tolerance value of 0.50 or higher is generally accepted, and the higher the tolerance value, the more useful the predictor is to the analysis as defined by $1-R^{2}$ (Tabachnich and Fidell, 2007). In terms of diagnostics, the condition index is measure of tightness or dependency of one variable on the others, and Tabachnick and Fidell (2007) suggest values less than 30 and variance proportions to be less than 0.50 for each item.

According to Garson (2012), residual analysis is used for three main purposes: 1) to spot heteroscadasticity (increasing error as the observed Y value increases); 2) to spot outliers (influential cases); and 3) to identify other patterns of error (error associated with certain ranges of $X$ variables). The studentised residual is similar to the standardized residual in measuring outliers and influential observations. This study has standardized residual $(\min =3.846$ and $\max =2.541)$ within expected interval $(-3.3$ or \pm 3$)$ and studentised residual $(\min =3.857$ and $\max =2.573)$ within 0 and \pm 3 . The normal distribution of this model has a mean of $0(0.000)$ and standard deviation closer to 1 (0.998) from standardized residuals (Tabachnick and Fidell, 2007). Cook's Distance measures how much an observation influences the overall model or predicted values as a summary measure of leverage and high residuals ( $D>1$ indicates a big outlier problem, that is, $\mathrm{D}>4 / \mathrm{N} \rightarrow$ sample size) (Baum, 2006; Stock and Watson, 2008). This study presents Cook's D for observations without outliers ( $\min =0.000$ and $\max =$ 
0.057) with value of D less than 1; "it does not have large effect on the regression analysis". Cook's distance, $C D_{i}=\left(p \sigma^{2}\right)^{-2}\left(\hat{Y}_{(i)}-\hat{Y}\right)^{T}\left(\hat{Y}_{(i)}-\hat{Y}\right)$. Fox $(1991: 34)$ further suggests as "a cut-off for deleting influential cases, values of D greater than 4 / $(\mathrm{N}-\mathrm{k}-1)$ ", when $\mathrm{N}=$ sample size and $\mathrm{k}=$ number of independents. In terms of residual statistics, Cook's D observations, leverage measures, and Mahalnobis distance indicated no outliers and the normal probability plot presented the normal plot of the residuals with points close to a diagonal line.

Discussion of Results: The empirical evidence in this study confirmed the moderate relationship between information sharing and predictor variables (quality information and integrated e-SCM system) in the perspective of managing bullwhip effect. In this study, quality information epitomizes knowledge domain, real-time information and level of integrity, trust and commitment in constrained formal contracts, third party controlled central hub or informal willingness to share information. Quality information sharing with real-time updated content should lower levels of inventory investment and improve demand order replenishment frequencies with less information distortion. Flynn, Huo, and Zhao, (2010:58-71) define integration as "the unified central control (or ownership) of several successive or similar process formerly carried on independently, sometimes the process integration is governed by contract means". The integration of e-SCM systems either through legally constrained (obligatory shared information) or proactively shared electronic information should produce real-time information content to obviate the amplification of consumer demand order variability. Highlighting the effect of supply chain integration on business performance, competitive advantage and supply chain management practices, Li and Lin (2006); Van der Vaart and Van Donk (2008); and Flynn et al. (2010) provide empirical evidence on relative synergistic value creation under supply chain integration in the form of either optimal or electronic information sharing. Shih et al. (2012:79) recommend knowledge sharing to improve supply chain performance in response to extreme challenges rather than the researcher's challenge of bullwhip effect. Nevertheless, this study achieved its objective by identifying relative explanatory variables on information sharing.

According to Hartono, Li, Na and Simpson, (2010:399) "the impact of the quality of shared information in inter-organizational systems (IOS) use on overall firm performance starts with top management support and IT infrastructure capability, and that these success factors positively impact the quality of shared information in IOS use. Moreover, the quality of shared information positively impacts operational supply chain performance, which, in turn, leads to improvements in overall firm performance". Yu, Ting and Chen (2010:2891) stress that, "effective supply chain management is not achievable by any single enterprise, but instead requires a virtual entity by faithfully integrating all involved partners, who should come up with the insightful commitment of real-time information sharing and collaborative management". The authors caution that sharing only capacity and/or inventory information, without sharing information on demand, interferes with manufacturers' production and causes misunderstandings, which can magnify the bullwhip effect.

This empirical research study revealed that top management support was considered the most critical factor affecting frequent interaction among supply chain partners to share value-based information. The other two factors (shared vision and trust) indicated a common desire to consider template-based and contract means to exert positive influence on information sharing. These supply chain information sharing strategies are expected to improve collaboration in line with the underlying ethical principle of integrity. However, the length of the supply chain network, and inconsistent, rigid inventory control policies among the supply chain partners, were considered to be negative factors influencing value-based information sharing in the retail supply chain. Despite channel alignment in retail supply chains, the literature suggests that a lengthy supply chain network and uncoordinated inventory policies would produce distorted information with subsequent loss of power from information disclosure or unnecessarily alerting competitors.

Information sharing is related to supply chain performance targets in the FMCG industry in terms of higher order fulfillment rates and achieving shorter order cycle time through integrated e-SCM systems. Integrated IT infrastructure capability and top management support (in terms of visible involvement, commitment, and participation of executives and the allocation of the required resources) are both significant antecedents of the quality of shared information. Hartono et al. (2010:406) demonstrate that the quality of shared information among supply chain partners is positively related to the supply chain's operational performance and, in turn, overall firm performance is directly impacted by supply chain performance. The respondents (76\%) further claimed that information sharing would achieve supply 
chain coordination and eventually mitigate cascading consumer demand order variability. The key subdimensions of information sharing, including electronic integration, quality information and velocity, are fundamental mechanisms to tame demand variability despite the recurrence of demand volatility and supply uncertainty resulting from the nature, format and timing of information. The first and middle levels of management associated information volatility with the length of supply chain channel networks coupled with the principles of information disclosure that are impediments to information sharing and the achievement of relative supply chain performance targets.

Managerial Implications: The integrated cross-enterprise model using electronic CPFR (e-CPFR) systems to achieve the common goal of serving end consumers should be upheld to reduce bullwhip effect and entrench the "reputation of on-time delivery and consistent product availability" through integrated and electronically-enabled information sharing. Integrated information technologies transcend extended enterprises to link with other businesses such as supply chain partners; this would enhance the quality of the information that is shared. Positive migration to a central supply chain distribution (CscD) system seems to subdue demand variability and supply uncertainty by consolidating information pooling on content, format and timing. It should also be noted that the central supply chain system would be supported by integrated e-SCM systems to achieve supply chain performance benefits through real-time information sharing capabilities and active coordination processes. This study found that information sharing could palliate cascading consumer demand order variability and seemed to be related to supply chain business performance outcomes. Its predictive ability came from integrated e-SCM systems and the quality of information. This means that there is a linear relationship between information sharing and integrated e-SCM system solutions and the quality of information shared in managing the challenges of bullwhip effect. Information sharing further presented the likelihood of improving supply chain business performance outcomes as it is less likely that the business would experience the presence of oscillating bullwhip effect. This implies that the top management should create necessary support to enhance the broader sharing of information within the network. Some majors should also be in place to promote a certain degree of trust among supply chain partners. The electronic central hub can further achieve the common goal through the integrated e-SCM systems to improve the supply chain competitiveness and performance.

\section{References}

Anderson, J. C. \& Narus, J. A. (1990). A model of distributor firm and manufacturer firm working partnerships. Journal of Marketing, 54, 42-58

Anderson, V. (2009). Research Methods in Human Resource Management.(2 ${ }^{\text {nd }}$ Ed.), London: Chartered Institute of Personnel Development.

Babbie, E. \& Mouton, J. (2001). The practice of social research. Cape Town: Oxford.

Balan, S., Vrat, P. \& Kumar, P. (2009). Information distortion in a supply chain and its mitigation using soft computing approach. Omega, 37, 282-299.

Barratt, M. \& Barratt, R. (2011). Exploring internal and external supply chain linkages: Evidence from the field. Journal of Operations Management, 29, 514-528.

Barratt, M. A. \& Oke, A. (2007). Antecedents of supply chain visibility in retail supply chains: A resourcebased theory perspective. Journal of Operations Management, 25(6), 1217-1233.

Bartlett, J. E., Kotrlik, J. W. \& Higgins, C. (2001). Organizational research: Determining appropriate sample size for survey research. Information Technology, Learning and Performance Journal, 19(1), 43-50.

Baum, C. F. (2006). An Introduction to Econometrics Using Stata. Princeton University: Stata Press.

Blumberg, B., Cooper, D. R. \& Schindler, P. S. (2008). Business Research Methods. New York: McGraw-Hill International.

Boccadoro, M., Marinelli, F. \& Valigi, P. (2006). H-infinity control of a Supply Chain Model. Proceedings of the $45^{\text {th }}$ IEEE Conference on Decision and Control, pp. 4387-4392.

Bowersox, D. J., Closs, D. J. \& Cooper, M. B. (2013). Supply Chain Logistics Management. (4th Ed.) Boston: McGraw-Hill

Brown, S. (2008). Measures of Shape: Skewness and Kurtosis. New York: Oakes Road Systems, Tompkins Cortland Community College.

Cachon, G. P. \& Fisher, M. (2000). Supply Chain inventory management and the value of shared information. Management Science, 46(8), 1032-1048. 
Chang, S. C., Lin, R. J., Chen, J. H. \& Huang, L. H. (2005). Manufacturing flexibility and manufacturing proactiveness: Empirical evidence from the motherboard industry. Industrial Management and Data Systems, 105(8), 1115-32

Chen, F. \& Yu, B. (2005). Quantifying the Value of Lead time Information in a single-location inventory system. Manufacturing Service Operations Management, 7(2), 144-151.

Chen, F. (2003). Information sharing and supply chain coordination. Operations Research and Management Science, 11, 341-422

Chen, I. J., Paulraj, A. \& Lado, A. (2004). Strategic purchasing, supply management and firm performance. Journal of Operations Management, 2(5), 333-343.

Cheng, T. C. E. \& Wu, Y. N. (2005). The impact of information sharing in a two-level supply chain with multiple retailers. Journal of the Operational Research Society, 56,1159-1165.

Chengalur-Smith, I., Duchessi, P. \& Gil-Garcia, J.R. (2012). Information sharing and business systems leveraging in supply chains: An empirical investigation of one web-based application. Information and Management, 49, 58-67

Childerhouse, P., Hermiz, R., Mason-Jones, R., Popp, A. \& Towill, D.R. (2003). Information flow in automotive supply chains - identifying and learning to overcome barriers to change. Industrial management and Data Systems, 103(7), 491-502.

Chopra, S. \& Meindl, P. (2007). Supply chain management: Strategy, planning and operations. (3 ${ }^{\text {rd }}$ Ed.), New Jersey: Pearson International edition.

Choudhury, B., Agarwal, Y. K., Singh, K. N. \& Bandyopadhyay, D. K. (2008). Value of Information in a Capacitated Supply Chain. INFOR, 46(2), 117-127.

Christopher, M. (2011). Logistics and Supply chain management. (4th Ed.), Boston: Pearson Publication.

Chu, S. \& Fang, W. (2006). Exploring the Relationships of Trust and Commitment in Supply Chain Management. Journal of American Academy of Business, 9(1), 224.

Cohen, J., Cohen, P., West, S. G. \& Aiken, L. S. (2003). Applied multiple regression/correlation analysis for the behavioral sciences. ( $3^{\text {rd }}$ Ed.), New York: Lawrence Erlboum Associates.

Collis, J. \& Hussey, R. (2009). Business Research: A practical guide for undergraduate students. Basingstoke: Palgrave.

Cooper, B. R. \& Schindler, P. S. (2008). Business Research Methods. (10 th Ed.), New York: McGraw-Hill International.

Croson, R., Donohue, K., Katok, E. \& Sterman, J. (2005). Order Instability in Supply Chains: Coordination Risk and the Role of Coordination Stock. PSU Working Paper

Darlington, R. B. (2009). Factor Analysis. Pp. 1-23, Available at: http://www.psych.cornell.edu/Darlington/factor.htm. (Accessed: 14 February 2012).

Davies, M. B. (2007). Doing a successful Research Project using Qualitative Methods. Basingstoke: Palgrave MacMillan.

Davies, T. (2006). Collaborate to innovate. Supply Management, 11(1), 34.

Davis, M. D. \& Heineke, J. (2005). Operations Management: Integrating manufacturing and services. $\left(5^{\text {th }}\right.$ ed.), Boston: McGraw-Hill.

Dong, Y., Xu, K. \& Dresner, M. (2007). Environmental determinants of VMI adoption: An exploratory analysis. Transportation Research Part E: Logistics and Transportation Review, 2, 355-369

Dougherty, P. J. (2011). Review of logistics and supply chain relationship and suggested research agenda. International Journal of Physical Distribution and Logistics Management, 42(1), 15-31.

Durugbo, C., Hutabarat, W., Tiwari, A. \& Alcock, J.R. (2011). Information channel diagrams: An approach for modeling information flows. Journal of Intelligent Manufacturing, Springer Science, 1-13, D01:10,1007/S10845-011-0523-7.

Emiliani, M. L. (2003). The inevitability of conflict between buyers and sellers. Supply Chain Management, 8(2), 107-15

Ferguson, M. \& Ketzenberg, M. (2006). Information sharing to improve retail product freshness of perishables. Production and Operations Management, 15(1), 57-73.

Fisher, I. M., (1997). What is the right Supply chain for your Product? Harvard Business Review, 75, 105116.

Flynn, B. B., Huo, B. \& Zhao, X. (2010). The impact of Supply chain integration on performance: A contingency and configuration approach. Journal of Operations Management, 28(1), 58-71

Forrester, J. W. (1958). Industrial dynamics - A major breakthrough for decision markers. Harvard Business Review, 36(4), 37-66.

Fox, J. (1991). Regression Diagnostics. Thousand, Oakes, CA: Sage Publications. 
Gao, T. S., Sirgy, J. M. \& Bird, M. M. (2005). Reducing buyer decision-making uncertainty in organizational purchasing: can supplier trust, commitment, and dependence help. Journal of Business Research, 58(4), 397-405.

Garson, G. D. (2012). Factor Analysis. North Carolina: Statistical Associates Publishing.

Gavirneni, S., Kapuscinski, R. \& Tayur, S. (1999). Value of information in capacitated supply chains. Management Science, 45(1), 16-24.

Ghosh, A. \& Fedorowicz, J. (2008). The role of trust in supply chain governance. Business Process Management Journal, 14(4), 453-470.

Gounaris, S. P. (2005). Trust and commitment influences on customer retention: insights from businessto-business services. Journal of Business Research, 58, 126-140.

Hair, Jr, J. F., Babin, B, Money, A. H. \& Samouel, P. (2003). Essentials of Business Research Methods. New York: John Wiley \& Sons, Inc.

Hamilton, L. (2006). Statistics with Stata. Cole: Thomson Books.

Hartono, E., Li, X., Na, K. \& Simpson, J. T. (2010). The role of the quality of shared information in interorganizational systems use. International Journal of Information Management, 30, 399-407.

Heffernon, T. (2004). Trust formation in cross-cultural business-to-business relationship. Qualitative Market Research, 7(2), 114-25.

Heikkila, J. (2002). From supply to demand chain management: efficiency and customer satisfaction. Journal of Operations Management, 20, 747-67.

Iskanius, P., Helaakoski, H., Alaruikka, A. M. \& Kipina, J. (2004). Transparent information flow in business networks by using agents. IEEE International Engineering Management Conference, 3, 13421346.

Jarrell, J. L. (1998). Supply chain economics. World Trade, 11(11), 58-61.

Kerlinger, F. N. (1986). Foundations of Behavioral Research. (3 ${ }^{\text {rd }}$ Ed.), New York: Holt, Rinehart and Winston.

Komiak, X. S. \& Benbasat, I. (2004). Understanding customer trust in agent-mediated electronic commerce, web-mediated electronic commerce, and traditional commerce. Information Technology and Management, 5(1/2), 181-207.

Kotabe, M., Martin, X. \& Domoto, H. (2003). Gaining from vertical partnerships: Knowledge transfer, relationship duration and supplier performance improvement in the U.S. and Japanese automotive industries. Strategic Management Journal, 24(4), 293-316.

Krejcie, R. V. \& Morgan, D. W. (1970). Determining sample size for research activities. Educational and Psychological Measurement, 30, 607-610.

Kwon, I. G. \& Suh, T. (2004). Factors Affecting the Level of Trust and Commitment in Supply Chain Relationships. The Journal of Supply Chain Management, 40(2), 4-14.

Lee, H., Padmanabhan, P. \& Whang, S. (1997). The Bullwhip effect in Supply Chains. Sloan Management Review, 38(3), 93-102.

Lee, J. \& Kim, Y. (1999). Effect of partnership quality on IS outsourcing: conceptual framework and empirical validation. Journal of Management Information Systems, 15(4), 26-61.

Li, S \& Lin, B. (2006). Accessing information sharing and information quality in supply chain management. Decision Support Systems, 42(3), 1641-1656.

Li, Z. \& Gao, L. (2008). The effects of sharing upstream information on product rollover. Production and Operations Management Society, 17(5), 522-531.

Lin, F., Huang, S. \& Lin, S. (2002). Effects of information sharing on supply chain performance in electronic commerce. IEEE Transactions on Engineering Management, 49(3), 258-268.

Mahalanobis, P. C. (1936). On the generalized distance in statistics. Proceedings of the National Institute of Science of India, 2(1), 49-55.

McIvor, R. \& Humphreys, P. (2002). Electronic commerce: supporting collaborative buyer-supplier relations. International Journal of Services Technology and Management, 3(2), 192-207.

Mentzer, J. T., Soonhong, M. \& Bobbit, L. M. (2004). Toward a unified theory of logistics. International Journal of Physical Distribution \& Logistics Management, 34(8), 606-627.

Moinzadeh, K. (2002). Multi-Echelon Inventory System with Information Exchange. Management Science, 48(3), 414-426.

Morgan, R. M. \& Hunt, S. D. (1994). The commitment-trust theory of relationship marketing. Journal of Marketing, 58(3), 20-38.

Myhr, N. \& Spekman, R. E. (2005). Collaborative supply-chain partnerships built upon trust and electronically mediated exchange. Journal of Business and Industrial Marketing, 20(4/5), 179-186.

Ng, W. K., Piplani, R. \& Viswanathan, S. (2003). Simulation workbench for analyzing multi-echelon supply chains. Integrated Manufacturing Systems, 14(5), 449-457. 
Ngai, E. W. T., Chau, D. C. K. \& Chan, T. L. A. (2011). Information technology, operational and management competencies for supply chain agility: Findings from case studies. Journal of Strategic Information Systems, 20, 232-249.

O'Brien, R. M. (2007). A Caution regarding rules of thumb for Variance Inflation Factors. Quality and Quantity, 41(5), 673-690.

Ouyang, Y. \& Daganzo, C. (2006). Characterization of the Bullwhip Effect in Linear, Time-Invariant Supply Chains: Some Formulae and Tests. Management Science, 52(10), 1544-1556.

Ouyang, Y. \& Daganzo, C. (2008). Robust tests for the bullwhip effect in supply chains with stochastic dynamics. European Journal of Operational Research, 185(1), 340-353.

Ouyang, Y. \& Li, X. (2010). The bullwhip effect in supply chain networks. European Journal of Operational Research, 201, 799-810.

Ouyang, Y. (2007). The effect of information sharing on supply chain stability and the bullwhip effect. European Journal of Operational Research, 182, 1107-1121.

Paton, S., Clegg, B., Hsuan, J. \& Pilkington, A. (2011). Operations Management. New York: McGraw-Hill.

Patterson, K. A., Grimm, C. \& Corsi, P. (2003). Adopting new technologies for supply chain management. Transportation Research, 39(2), 95-121.

Paul, D. L. \& McDaniel, R. (2004). A field study of the effect of interpersonal trust on virtual collaborative relationship performance. MIS Quarterly, 28(2), 183-227.

Rinehart, L. M., Eckert, J. A., Handfield, R. B., Page, Jr, T. J. \& Atkin, T. (2004). An assessment of suppliercustomer relationships. Journal of Business Logistics, 25(1), 25-43.

Sekaran, U. \& Bougie, R. (2009). Research Methods for Business: A Skill Building Approach. (5th Ed.), New York: Wiley \& Sons.

Sekaran, U. (2003). Research Methods for business: A Skill Building Approach. (4 ${ }^{\text {th }}$ Ed.), New York: John Wiley \& Sons Inc.

Sheu, C., Yen, H. R. \& Chae, B. (2006). Determinants of supplier-retailer collaboration: evidence from an international study. International Journal of Operations and Production Management, 26(1/2), 24.

Shih, S. C., Hsu, S. H. Y., Zhu, Z. \& Balasubramanian, S. K. (2012). Knowledge sharing - A key role in the downstream supply chain. Information \& Management, 49, 70-80.

Shimizu, K. \& Hitt, M. A. (2004). Strategic flexibility: Organizational preparedness to reverse ineffective strategic decisions. Academy of Management Executive, 18, 44-60.

Simchi-Levi, D., Kaminsky, P. \& Simchi-Levi, E. (2008). Designing and Managing in supply chain: Concepts, Strategies \& Case Studies. ( $3^{\text {rd }}$ Ed.), New York: McGraw-Hill/Irwin.

Spekman, R. E., Kamauff, J. W. \& Myhr, N. (1998). An empirical investigation into supply chain management: a perspective on partnerships. Supply Chain Management, 3(2), 53-67.

Stevens, J. P. (2002). Applied multivariate Statistics for the Social Sciences. (4th Ed.), New York: LEA.

Stock, J. H. \& Watson, M. W. (2008). Introduction to Econometrics. (2 ${ }^{\text {nd }}$ Ed.), Boston: Pearson Addison Wesley.

Tabachnick, B. G. \& Fidell, L. S. (2007). Using Multivariate Statistics. (5 ${ }^{\text {th }}$ Ed.), Boston: Pearson International Edition.

Van der Vaart, T. \& Van Donk, D. (2008). A critical review of survey-based research in supply chain integration. International Journal of Production Economics, 111, 42-55.

Van Weele, A. J. (2010). Purchasing and Supply Chain Management. (5 ${ }^{\text {th }}$ Ed.), UK: Cengage Learning.

Vijayasarathy, L. R. (2010). An investigation of moderators of the link between technology use in the supply chain and supply chain performance. Information and Management, (47), 364-371.

Wang, E. T. G. \& Wei, H. L. (2007). Interorganizational Governance Value Creation: Coordinating

Welman, J. C., Kruger, S. J. \& Mitchell, B. C. (2005). Research Methodology. (3rd Ed.), Cape Town: Oxford University Press Southern Africa.

Wisner, J. D. \& Stanley, L. L. (2008). Process Management: Creating Value along the Supply Chain, Text and Cases. Australia: Thomson South-Western.

Wu, D. Y. \& Katok, E. (2006). Learning, communication, and the bullwhip effect. Journal of Operations Management, 24, 839-850.

Wu, I. L. \& Chuang, C. H. (2009). Analyzing contextual antecedents for the stage-based diffusion of electronic supply chain management. Electronic Commerce Research and Applications, 8(6), 302-314.

Yu, M., Ting, S. \& Chen, M. (2010). Evaluating the cross-efficiency of information sharing in supply chains. Expert Systems with Applications, 37, 2891-2897.

Zhao, X., Xie, J. \& Zhang, W. J. (2002). The impact of information sharing and order-coordination on supply chain performance. Supply Chain Management: An International Journal, 7(1), 24-40. 